\title{
Psycho-social risks at work: stress and coping strategies in oncology nurses
}

\author{
Sandra da Fonte Sousa Gomes ${ }^{1}$ \\ Margarida Maria Magalhães Cabugueira Custódio dos Santos² \\ Elisabete Teresa da Mata Almeida Carolino ${ }^{3}$
}

\begin{abstract}
Objective: to identify sources of stress and coping strategies in nurses who work in three Head and Neck Surgery Oncology Services, in three central hospitals in Portugal. Method: a crosssectional descriptive-exploratory study, whose sample was made up of the 96 nurses from the three services. The following were used in the data collection: a socio-demographic questionnaire; the 12-item General Health Questionnaire; and the Occupational Stress Inventory; Brief COPE. Results: reasonable levels of general health were ascertained. The most-mentioned stressors were: burden with work; low pay; the physical space where they work; emotionally-disturbing situations and lack of recognition of the profession. The most-used coping strategies were: planning; active coping; acceptance and self-distraction. Conclusion: the stressors identified are mainly related to organizational aspects and work conditions, and the coping strategies chosen are aimed at resolving problems and improving the nurses' well-being. A significant percentage of the nurses presents high levels of pressure and depressed emotions. The results presented corroborate previous studies which warn of the importance of developing strategies for preventing these stress levels.
\end{abstract}

Descriptors: Nursing; Medical Oncology; Burnout, Professional; Adaptation, Psychological.

\footnotetext{
${ }^{1}$ MSc, RN, Instituto Português de Oncologia Francisco Gentil, Lisboa, Portugal.

${ }^{2} \mathrm{PhD}$, Cordinator Professor, Departamento de Ciências Sociais e Humanas, Escola Superior de Tecnologia da Saúde de Lisboa, Lisboa, Portugal. Professor, Núcleo de Psicologia da Saúde, Faculdade de Psicologia de Lisboa, Lisboa, Portugal.

${ }^{3}$ MSc, Adjunct Professor, Departamento das Ciências Naturais e Exatas, Escola Superior de Tecnologia da Saúde de Lisboa, Lisboa, Portugal.
}

Corresponding Author:

Sandra da Fonte Sousa Gomes

Instituto Português de Oncologia de Lisboa, Francisco Gentil E.P.E.

Praceta D. João II, 4, Complemento $3 \mathrm{~A}$

CEP: 2660-453, Santo António dos Cavaleiros, Portugal

E-mail: meixidinha@hotmail.com
Copyright (c) 2013 Revista Latino-Americana de Enfermagem This is an Open Access article distributed under the terms of the Creative Commons Attribution Non-Commercial License (CC BY-NC).

This license lets others distribute, remix, tweak, and build upon your work non-commercially, and although their new works must also acknowledge you and be non-commercial, they don't have to license their derivative works on the same terms. 


\section{Introduction}

In recent decades, the observation of the implications and consequences of transformations in the work context has called attention to the relevance of studying psychosocial risks at work. These are defined as those aspects which are related to the design, management and organization of the work, as well as to the social and environmental contexts, which have the potential to cause physical, social or psychological harm, and which may be experienced through occupational stress $^{(1)}$. Recent data from the European Risk Observatory indicates that between $50 \%$ and $60 \%$ of lost work days are related to the phenomenon of stress ${ }^{(2)}$. The National Institute for Occupational Safety and Health defines occupational stress, or workplace stress, as the harmful physical and emotional responses that occur when the requirements of the job do not match the caᄀpabilities, resources, or needs of the worker ${ }^{(3)}$. According to a broad set of studies, stress is responsible for a reduction in the quality of professional performance, reduction in the individual's satisfaction and well-being, personal stagnation and absenteeism from work ${ }^{(1)}$. Individual factors and social resources can moderate the reaction to the causes of occupational stress ${ }^{(3)}$. In health institutions, professional stress is mentioned in the literature as a determinant for reduction in the quality of the services provided, an increase in the numbers of errors, and raised financial costs ${ }^{(3)}$.

In the area of healthcare, nursing professionals are subject to innumerable stressful situations on a daily basis, both from their closeness to the patients and the specific nature of the tasks they carry out, and from the characteristics of the work environment and the organization of the work ${ }^{(4)}$. This class of professionals, which has been the subject of various studies in recent years, is particularly exposed to high levels of pressure and stress ${ }^{(4-8)}$. As a result, the interest in the studying of stress in nursing is justified by the nature of the services provided, as the quality and efficacy of the nurses' work can have a decisive impact on the quality of the care given to the patients ${ }^{(4,8)}$. Care provision, in the specific area of oncology, is highly demanding and complex, given the characteristics inherent to it, namely: prolonged and aggressive treatments, with side effects; mutilating surgery; the patients' suffering, and their feelings of fear, despair and panic; and death. These have been evidenced as stressing factors, and are associated with the oncology nursing professional's psychological suffering ${ }^{(9-10)}$.
The experience of stress is accompanied by the process of coping(11). Coping presupposes the mobilization of resources, through which the individual will use cognitive and behavioral efforts to manage the internal and external demands which result from interaction with the environment, which are assessed as threatening, and which exceed the individuals' capacity to cope ${ }^{(11)}$. According to previous studies, in order to deal with occupational stress, oncology nurses use coping strategies of the following types: preservation ${ }^{(12)}$ (demarcation of limits in involvement in situations which cause stress), reconstruction ${ }^{(12)}$ (actions which allow the reconstruction of a balanced identity) and reevaluation $^{(9,12-13)}$ (the re-analysis of situations in terms of meaning and alternatives for their resolution).

Caring for an oncology patient in Head and Neck Surgery is especially threatening to the nurse's balance. Tumors of the head and neck causes disabilities at various levels, and may compromise the functional integrity in mastication, the voice, speech, swallowing and articulation; they can lead to psychological and esthetic harm; and they lead to occupational disturbances in the patient's life ${ }^{(14)}$. It should be added that head and neck surgery entails inescapable sequelae, sometimes more mutilating than the disease in its initial stage, causing mental, emotional and physical suffering(15). Although the potential for stress among these professionals has been confirmed empirically, investigations on occupational stress in oncology nurses working in the area of Head and Neck Surgery were not found in the literature review which preceded the present study. So as to remedy this shortcoming, the following was defined as a general objective for this investigation: to identify the sources of stress and the coping strategies used by oncology nurses, in the Head and Neck Surgery Service.

\section{Method}

This is a cross-sectional study, with a descriptive and exploratory character, undertaken with nurses of the Head and Neck Surgery services in three Head and Neck Surgery oncology services, in three Central Hospitals in Portugal. The target population was defined as all the nurses who met the following criteria: 1) exercising roles in the direct provision of care to the patient; 2) who were no longer in their probationary period and 3) voluntary participation in the study. The sample was made up of 96 nurses, which corresponds to the total number of individuals in the population. 
The process of data collection began with a written request to the three health institutions' Nursing Administration and Management Councils, presenting information on the study's objectives and the questionnaires to be used, guaranteeing the confidentiality of the results and the anonymity of the respondents. The study was officially authorized by these Councils, which, taking into account the target population and type of study, dispensed with the decision of the Ethics Committees. The collection of the questionnaires took place between January and April 2011.

The following were used in the data collection: I) Socio-Demographic Questionnaire; II) The 12-item General Health Questionnaire (validated for the Portuguese population)(16); III) The Occupational Stress Inventory ${ }^{(17)}$; and IV) The Brief COPE(18) (adapted for the Portuguese population) $)^{(19)}$.

The 12-item General Health Questionnaire is a reduced version of the original instrument, the General Health Questionnaire, and permits the evaluation of the individual's general perception regarding his or her health(16). This questionnaire, validated for the Portuguese population(16), is made up of 12 items, each being evaluated on a Lickert scale with 4 points: for the negative items, the response option varies from " 1 - No, absolutely" to "4 - Much more than normally"; for the positive items, the response option varies from "1 - Better than normally" to "4 - Much less than normally". The present study considered only the global evaluation of the 12 items, having obtained an Alpha Cronbach value equal to 0.829 .

The Occupational Stress Inventory is made up of 23 items and allows the respondent to assess, on a 4 point Lickert scale ("1-Not stressful" to "4Very stressful") a set of situations which can trigger stress $^{(17)}$. This questionnaire had recently been used in a study on occupational stress and coping strategies in physiotherapists ${ }^{(17)}$. The Occupational Stress Inventory integrates two dimensions related to occupational stress: the Functional Dimension and the SocioEmotional Dimension(17). The Functional Dimension is to do with stressors associated with aspects intrinsic to the health professionals' tasks, while the Socio-Emotional Dimension is to do with the stressors associated with the emotional and socio-emotional aspects relating to the tasks performed by the health professionals(17). In this study, the Functional dimension presented an Alpha Cronbach value of 0.824, and the SocioEmotional dimension presented an Alpha Cronbach value of 0.698 .
The Brief-COPE ${ }^{(18)}$ (adapted to the Portuguese population $)^{(19)}$ was used to identify the coping strategies used by the individual when she faces potentially stresscreating situations. The Brief-COPE is an abbreviated version of the COPE Inventory, and is made up of 14 dimensions, each with two items: active coping; planning; positive reframing; acceptance; humor; support in religion; use of emotional support; use of instrumental support; self-distraction; denial; venting; substance use; behavioral disengagement and self-blame ${ }^{(18)}$. Each item has a 4-point Lickert response scale: "1 - I haven't been doing this at all" to "4 - I've been doing this a lot", in which the subject must evaluate the option which best describes her actions ${ }^{(18)}$. In this study, the Brief-COPE obtained an Alpha Cronbach value of 0.872 .

The data obtained was processed using the SPSS software (Statistical Package for the Social Sciences) version 18.0. In this way, the systematization of the information obtained from the quantitative data was subjected to techniques of descriptive statistics (absolute frequencies ( $n$ ) and relative frequencies (\%), and measures of central tendency). In relation to the variables under study, a bivariate analysis of the data was undertaken. In the crossing of the socio-demographic factors with the 12-item General Health Questionnaire and with the Brief-COPE, the non-parametric MannWhitney $U$ test was used ( $p>0.05$ ); and in the crossing of these variables with the Professional Stress Inventory, the independent samples $t$ test was used $(p<0.05)$. Later, correlational analysis was used between the socio-demographic factors with the data collection instruments used. In all analyses of statistical inference, a significance level of $5 \%$ was used.

\section{Results}

The majority of the 96 nurses making up the sample was female $(n=79,82.29 \%)$, with a mean age of approximately 31 years old, a minimum age of 22 years old, and a maximum age of 53 years old, single $(n=51$, $53.1 \%)$, and without children $(n=66,68.8 \%)$. The mean time in which they had worked in the area of oncology was 7 years 8 months, the minimum period was 5 months, and the maximum was 31 years. Regarding length of service in Head and Neck Surgery, the nurses had a mean of 6 years 6 months, with a minimum time of exercising activities in the service of 5 months, and a maximum time of 30 years. The majority of the nurses ( $n=78,80.65 \%$ ) had not been trained specifically in oncology, although, of the nurses who had been 
trained specifically in oncology, the Oncology Nursing Course was that which had been undertaken the most $(n=12,70.6 \%)$.

In order to evaluate the respondents' perception of their general health as a whole, (general score) the scores of all the items composing the 12-item General
Health Questionnaire were added together. The general score varies between $12(12 \times 1)$ and $48(12 \times 4)$, the mean point being $30((48+12) / 2)$. Higher values reveal a lower quality of general health. Table 1 shows that the sample's General Health value is below the cut-off point, indicating reasonable values for general health.

Table 1 - Evaluation of the general score of the 12-item General Health Questionnaire. Porto, Coimbra, Lisbon, Portugal, 2011

\begin{tabular}{lcccccc}
\hline \multicolumn{4}{c}{ Descriptive Statistics (N=96) } & & \\
\hline Score of the 12-item General Health Questionnaire & 5 & Minimum & Maximum & Mean & Standard Deviation & Midpoint \\
\hline
\end{tabular}

Based in the descriptive statistics analysis of the dimensions of the 12-item General Health Questionnaire, it was ascertained that $30.2 \%(n=29)$ of the respondents mentioned feeling "sad and depressed" and "constantly under pressure". Considering the variables of "gender" and "marital status", it was observed that there were no statistically-significant differences between the two sexes in relation to the perception of the quality of general health (Mann-Whitney $U$ test $(p=0.563)$ ) and between the group of those who are married, and the group of those who are single (Mann-Whitney $U$ test $(p=$ 0.938)).

From the descriptive analysis of the Professional Stress Inventory it was ascertained that the majority of the responses obtained varied between the option "2-Little Stressful" and "3-Stressful". The situations considered "2-Little Stressful" are: the "Interdependence of responsibility" (58.3\%, $n=56)$, the "Lack of material resources in the services" $(52.1 \%, n=50)$ and the "Interpersonal conflicts with the auxiliary nurses" $(52.1 \%, n=50)$. As "3-Stressful" the largest percentage of the individuals considered: the "Work Burden" $(52.1 \%, n=50)$, the "Physical space in which the work is carried out" $(46.9 \%, n=45)$ and the "Situations of death and/or illness with an emotionally negative character" (46.9\%, $n=45)$. The respondents considered as "4-Very Stressful": the "Lack of social recognition of the profession" (44.8\%, $n=43)$ and the "Low pay" $(51 \%, n=49)$. Considering the variable "gender" it was ascertained that in relation to gender there are statistically-significant differences in the Functional Dimension and the Socio-Emotional Dimension, with female individuals presenting significantly higher values, that is, the female nursing professionals attribute a higher degree of stress to the occupational stressors of both the Dimensions ( $t$ test for independent samples $(p=0.049$ and $p=0.020))$. In relation to the "marital status" variable, statistically-significant differences were not observed for the Functional Dimension and for the Socio-Emotional Dimension in relation to the married group and the single (separated/divorced) group ( $t$ test for independent samples $(p=0.715$ and $p=0.564)$ ).

For evaluating the most-used coping strategies, scores were constructed for the 14 dimensions of the Brief-COPE. The midpoint of all the dimensions is the same, therefore values close to or higher than 5 show a higher frequency of use of each one of the dimensions - Coping strategies (Table 2).

Thus, the strategies used most by the respondents were: Planning, Active Coping, Acceptance, Selfdistraction and Positive Reframing. From the descriptive analysis of the Brief-COPE, the option "I've been doing it, on average" stands out, obtaining the highest response percentages in relation to Active Coping (Item 2 - "I have directed my efforts towards doing something to resolve the situation which causes me stress" - 56.3\%, $n=54$; Item 7 - "I have carried out actions to improve the stressing situation" - 45.8\%, n=44), Planning (Item 14 "I have tried to find a strategy on what to do" $-47.9 \%$, $\mathrm{n}=46$; Item 25 - "I have reflected a lot on what steps to take" - 40.6\%, n=39), Acceptance (Item 20 - "I have come to accept the reality of the fact of this situation happening" - 49\%, n=47; Item 24 - "I have learned to live with this" $-39.6 \%, \mathrm{n}=38$ ), Positive Reframing (Item 12 - "I have tried to see the stressful situation from a different perspective so as to make it seem more positive" - 33.3\%, n=32; Item 17 - "I have tried to find something good in what is to happen" - $42.7 \%, \mathrm{n}=41$ ) and Selfdistraction (Item 1 - "I have turned to work or to other activities to distract my mind from the issues which cause me stress" - 39.6\%, n=38; Item 19 - "I have done other things so as to think less about the stressful situation, 
such as going to the cinema, watching television, reading, daydreaming, sleeping or going shopping" $35.4 \%, n=34)$. Considering the variable "gender", it was ascertained that statistically-significant differences are only found regarding substance use, with the male group having higher values (Mann-Whitney $U(p=0.011)$ ). In relation to the variable "marital status", statisticallysignificant differences were not observed between the 'married' group and the 'single' group (Mann-Whitney $U$ ( $p>0.05$, for all of the coping strategies)).
In relation to the correlations between the coping strategies and the variables of general health and sociodemographic data, it was ascertained that the results of the 12-item General Health Questionnaire correlate positively and weakly with the coping strategies of Self-distraction, Denial, and Behavioral Disengagement (Table 3), that is, one may observe the existence of a relation between worse levels of general health and recourse to these coping strategies.

Table 2 - Evaluation of the scores of the Brief-COPE. Porto, Coimbra, Lisbon, Portugal, 2011

\begin{tabular}{|c|c|c|c|c|c|}
\hline \multicolumn{6}{|c|}{ Descriptive Statistics ( $\mathrm{N}=96)$} \\
\hline Score & Minimum & Maximum & Mean & Standard Deviation & Mid-point \\
\hline Active Coping & 2 & 8 & 5.41 & 1.426 & 5 \\
\hline Planning & 2 & 8 & 5.55 & 1.608 & 5 \\
\hline Positive Reframing & 2 & 8 & 4.93 & 1.489 & 5 \\
\hline Acceptance & 2 & 8 & 5.06 & 1.375 & 5 \\
\hline Humor & 2 & 8 & 4.11 & 1.666 & 5 \\
\hline Support in Religion & 2 & 8 & 3.61 & 1.707 & 5 \\
\hline Use of Emotional Support & 2 & 8 & 4.47 & 1.479 & 5 \\
\hline Use of Instrumental Support & 2 & 8 & 4.58 & 1.513 & 5 \\
\hline Self-distraction & 2 & 8 & 4.94 & 1.588 & 5 \\
\hline Denial & 2 & 8 & 3.04 & 1.313 & 5 \\
\hline Venting & 2 & 8 & 4.54 & 1.399 & 5 \\
\hline Substance Use & 2 & 6 & 2.14 & .535 & 5 \\
\hline Behavioral disengagement & 2 & 6 & 2.79 & 1.075 & 5 \\
\hline Self-blaming & 2 & 8 & 3.85 & 1.444 & 5 \\
\hline
\end{tabular}

Table 3 - Correlations between the 12-item General Health Questionnaire and the Brief-COPE: Pearson correlation coefficient ( $r$ ) and level of significance (p). Porto, Coimbra, Lisbon, Portugal, 2011

\begin{tabular}{llccc}
\hline & & Self-distraction & Denial & $\begin{array}{c}\text { Behavioral } \\
\text { disengagement }\end{array}$ \\
\hline \multirow{2}{*}{ 12-item General Health Questionnaire } & $r$ & 0.205 & 0.342 & 0.382 \\
& $p$ & 0.045 & 0.001 & 0.000 \\
\hline
\end{tabular}

\section{Discussion}

Through this study, the intention is to assess the general perception of health and identify sources of stress and coping strategies in a sample of 96 oncology nurses from the Head and Neck Surgery Services.

It was ascertained that the population under study presents reasonable values for general health. It stands out, however, that a significant percentage of the nurses mentions having felt sadder or more depressed than normal, and also to have felt more pressure than normal. These results confirm previous studies which note that in spite of generally evaluating their health positively, the nurses frequently present high values in relation to depressed or anxious states ${ }^{(20)}$.
In relation to the sources of stress identified in this study, those related to low pay and lack of social recognition of the profession stand out, backing up previous investigations ${ }^{(6-8)}$. Lack of social recognition of the profession is, actually, one of the problems mentioned most by a set of health professionals (Nurses, technical diagnostic and therapeutic personnel) whose academic training has only recently been certified as a degree-level qualification; this academic recognition, however, has not always been accompanied by effective changes in the regulations of these professionals, who, in many cases, continue to feel there to be obstacles to the full development of their professional potential. A high number of the subjects also considered as stressful those situations related to functional and organizational 
aspects, such as the physical space where the activities are carried out, the work overload, and situations related to emotional aspects, such as facing disease, death and other situations with emotionally-negative characters. These results are similar to those found in other studies with similar samples ${ }^{(5-6,9)}$. The situations involving death and/or disease with an emotionally-negative character constitute one of the stressors most-evidenced by the investigators in widely-differing areas of nursing, although they particularly stand out in the studies on nurses in the area of oncology $y^{(6,9,21)}$. In one study ${ }^{(21)}$ with nurses from different oncological institutions in Sweden, it was observed that the levels of stress varied from low to serious, and the main sources of stress identified were: caring for young oncology patients, dealing with situations of death, and low efficacy in relieving the patient's suffering. The rating of the work overload as a stressor can be linked to the type of care provided to the oncological patient (normally, complex care), to the insufficient number of nurses in the care provision, and to the fact that the nurses perform roles outside their work ambit (e.g. administrative roles or functions in the social area). Regarding the physical spaces in the health institutions, these tend not to be very ergonomic, that is, they are little-adapted to the needs of the health professionals and are little-suited to the needs of the patients, which interferes with the dynamics of the nursing professionals' work. Similarly, in one study(22) undertaken with Portuguese nurses in an Intensive Care Unit, it was ascertained that the inappropriate physical conditions and the work burden constitute a source of stress. In relation to the sources of stress, it was also observed that the female nursing professionals attribute a greater degree of stress to the occupational stressors than do the males. This evidence may be attributed to the fact that female nursing professionals undertake, in addition to their work activities, multiple roles ${ }^{(23)}$ related to aspects of family and domestic life. In this regard, one study ${ }^{(4)}$ is indicated undertaken with nurses from five Brazilian public university hospitals, the results of which evidenced that the female nursing professionals experience feelings of guilt due to the lack of attention given to their children as a result of their jobs, triggering psychosomatic symptoms which compromise the general quality of life of these individuals and close family members.

In relation to the type of coping strategies, those most used by the nurses were: Planning, Active Coping, Acceptance, Self-distraction, and Positive Reframing. The strategy used least by the nurses was Substance Use.
Planning and Active Coping are coping strategies which, essentially, aim to resolve the stressing event/situation. Also, in a study ${ }^{(6)}$ carried out in five Oncology Hospitals in Turkey, it was ascertained that the coping strategies used most by oncology nurses were actions involving the reevaluation of the potential stressor and the elaboration of ways of resolving it. The preferential use of this type of strategies may be related to the pragmatic orientation of planning and resolution of problems, which is traditionally followed in these professionals' academic training, but which may also be related to the existence of good social support. The results of one study ${ }^{(13)}$ with Brazilian nurses in a Burns Unit and in a Chronic Pain and Palliative Care Unit indicate this to be the case, as they confirm that the work context's psychological demands and adverse conditions are mitigated when the professionals have high levels of positive social interaction. Acceptance, SelfDistraction and Positive Reframing are coping strategies focussed on emotion. The individual uses this type of coping when she concentrates efforts on herself, with the aim of altering her comprehension of the stressor and reducing the malaise produced. In relation to the coping strategy of Acceptance, this represents a response pattern which is essentially characterized by a resigned acceptance of the stressing situation, reducing its value. This result is opposite to that found in a study(5) with Portuguese nurses, in which Acceptance constituted one of the less-used strategies. Recourse to Self-distraction is frequently expressed in involvement in activities with the aim of avoiding the stressing event. Although this may have a positive character, the systematic and exclusive use of this strategy can make the nurse withdraw from the reality which she needs to face in her day-to-day, and may not allow more active resolutive strategies. Positive Reframing, which is related to the individual's attempt to re-structure the stressing event, and aims to find more favorable aspects which permit her personal or professional growth, was also identified in one study ${ }^{(9)}$ with oncology nurses, as the most-used coping strategy focussed on emotion. Similar results were found in another study ${ }^{(24)}$ on psychological suffering in oncology nurses, which showed that the respondents referred to "not getting involved" with the oncological patient, family, and/or work colleagues, the aim being not to establish emotional ties.

Supporting the results of previous investigations(25), the present study ascertained a significant negative correlation between general health and avoiding coping strategies based on avoidance or postponement, such as Self-distraction, Denial, and Behavioral Disengagement. 
This result supports the idea that strategies centered on the removing of the individual from the source of stress can be protective in specific crisis situations or situations which are impossible to resolve, but do not promote physical or emotional balance in situations which are prolonged over time and which require the individual's active participation.

In relation to the study's limitations, these are related to the small scale of the sample under study, which does not permit it to be generalized. It should be noted, however, that the sample used included all the nurses of the services where the study was carried out.

\section{Conclusion and practical implications}

It is considered that the results obtained can constitute an important contribution to the understanding of the factors of occupational stress in oncology nursing for the development of actions which prevent adverse reactions in the nursing professionals' health and well-being, and which consequently promote the quality of the services provided to the patient. In this preventive context, it is essential to implement strategies which aim to: (1) improve the organization of the work and the distribution of the roles, such that the nurses' abilities and personal and collective resources may be respected and used effectively; (2) improve the communication channels (improvement of information exchange between teams), making such communication more effective; (3) make professional development and growth possible (valorization of the competences of, and the profession of, nursing); (4) set up continuing training programs (training at work or promotion of training on courses giving qualifications in generic or specific skills); and (5) develop programs for stress support and prevention (discussion groups and support/ psycho-social support groups to help monitor stress and resolve problematic situations).

\section{References}

1. Cox T, Griffiths AJ, Rial-Gonzáles E. El estrés relacionado con el trabajo. Agencia Europea para la Seguridad y la Salud en Trabajo [Internet] 2005; [acesso 23 maio 2011] Disponível em http://osha.europa.eu/es/ publications/reports/203.

2. Observatório Europeu dos Riscos. Aumenta o número de pessoas que enfrentam riscos psicossociais no trabalho [Internet] 2008; [acesso 20 maio 2011] Disponível em http://osha.europa.eu/pt/press/pressreleases/news_article.2008-01-30_stress.
3. National Institute for Occupational Safety and Health (USA). Exposure to Stress: Occupational Hazards in Hospitals [Internet] 2008; Publication n. 136. [acesso 8 nov 2010] Disponivel em http://www.cdc.gov/niosh/ docs/2008-136/.

4. Mininel VA, Baptista PCP, Felli VE. Psychic workloads and strain processes in nursing workers of brazilian university hospitals. Rev. Latino-Am. Enfermagem. 2011;19(2):340-7.

5. McIntyre T, McIntyre S, Silvério J. Respostas de stress e recursos de coping nos enfermeiros. Anal Psicol. 1999;17:513-27.

6. Isikhan V, Gomes T, Danis Z. Job stress and coping strategies in health care professionals working with cancer patients. Eur J Oncol Nurs. 2004;8:234-44.

7. Glazer S, Gyurak A. Sources of occupational stress among nurses in five countries. Int J Intercult Relations. 2008; 32:49-66.

8. Gomes RA, Cruz JF, Cabanelas S. Stress ocupacional em profissionais de saúde: um estudo com enfermeiros Portugueses. Psicol Teoria Pesqui. 2009; 25(3):307-18.

9. Rodrigues $A B$, Chaves EC. Stressing factors and coping strategies used by oncology nurses. Rev. LatinoAm. Enfermagem. 2008;16(1):24-8.

10. Faria DAP, Maia EMC. Nursing professionals' anxiety and feelings in terminal situations in oncology. Rev. Latino-Am. Enfermagem. nov-dez 2007; 15(6):1131-7.

11. Lazarus RS, Folkman S. Stress appraisal and coping. New York: Springer; 1984.

12. Ekedahl M, Wengstrom Y. Nurses in cancer careCoping strategies when encountering existential issues. Eur J Oncol Nurs. 2006;10:128-39.

13. Negromonte MRO, Araujo TCCF. Impact of the clinical management of pain: evaluation of stress and coping among health professionals. Rev. Latino-Am. Enfermagem. 2011;19(2):238-44.

14. Alvarenga LM, Ruiz MT, Pavarino-Bertelli EC, Ruback MJC, Maniglia JV, Goloni-Bertollo EM. Epidemiologic evaluation of head and neck patients in a university hospital of Northwestern São Paulo State. Rev Bras Otorrinolaringol. 2008;74(1):68-73.

15. Vasconcellos-Silva PR, Nolasco PTL. Dialética da autonomia dos equilíbrios nos conflitos entre pacientes e cirurgiões Oncológicos. Rev Saúde Pública. 2009;43(5):839-45.

16. Laranjeira CA. General health questionnaire-12 items: adaptation study to the Portuguese population. Epidemiol Psichiatr Soc. 2008;17(2):148-51. 
17. Santos MC, Barros L, Carolino E. Occupational stress and coping resources in physiotherapists: a survey of physiotherapists in three general hospitals. Physiotherapy. 2010;96:303-10.

18. Carver CS. You Want to Measure Coping But Your Protocol's Too Long: Consider the Brief COPE. Int J Behav Med. 1997;4(1):92-100.

19. Sabino A, Santos M, Carvalhais J, Carolino E. Factores de risco de stress relacionado com o trabalho e níveis de stress percebido no corpo académico: estudo numa instituição de ensino superior politécnico. Portugal: Segurança e higiene ocupacionais - SHO; 2011. p. 564-9.

20. Moore $K$, McLaughlin D. Depression: the challenge for all healthcare professionals. Nurs Stand. 2003;12$18 ; 17(26): 45-52$.

21. Ekedahl M, Wengstrom Y. Nurses in cancer carestress when encountering existential issues. Eur J Oncol Nurs. 2007;11:228-37.

22. Rodrigues VMCP, Ferreira ASS. Stressors in nurses working in Intensive Care Units. Rev. Latino-Am. Enfermagem. 2011;19(4):1025-32.

23. Guerrer FJL, Bianchi ERF. Caracterização do estresse nos enfermeiros de unidades de terapia intensiva. Rev Esc Enferm USP. 2008;42(2):355-62.

24. Avellar LZ, Iglesias A, Valverde PF. Sofrimento psíquico em trabalhadores de enfermagem de uma unidade de oncologia. Psicol Estudo. 2007;12(3):475-81.

25. Coelho JAPM, Albuquerque FJB, Martins CR, D'Albuquerque HB, Neves MTS. Coping em Jovens frente à Expectativa de Inserção Ocupacional e Indicadores de Depressão. Psicol Teoria Pesqui. 2008;24(4):527-34. 